\title{
PERSONAL RECOLLECTIONS OF A GOOD EXPERIMENT
}

\author{
Erle Nelson \\ Archaeology Department, Simon Fraser University, Burnaby, British Columbia, Canada. Email: dewart@sfu.ca.
}

ABSTRACT. This is the written version of a retrospective talk given at the 20th Radiocarbon Conference in Hawaii, 2009. As requested, this is not a scholarly work, but simply a personal, subjective account of how a good experiment in the field of radiocarbon dating came about. It differs from the talk itself only in that I have eliminated some sideline commentary so that I can add a few thoughts originally intended for the end, when I had talked myself out of time.

\section{INTRODUCTION}

A few months ago, John Southon phoned to ask me if I would be attending this conference. I had no plans to come, as I will retire in 3 months' time, and over the past few years I have quietly stopped research in the radiocarbon field. I had nothing new to report, but John wasn't interested in something new from me; he wanted something old. He asked if I would recount to you how the experiment described in the Science paper entitled "Carbon 14: Direct detection at natural concentrations" (Nelson et al. 1977) came to be done almost exactly 32 years ago today.

I could not understand why anyone would be interested in hearing an old professor ramble on about ancient history, but he then made me an offer I couldn't refuse (he would pay the bills) and so here I am, a sort of talking artifact. Perhaps that is appropriate for a field so devoted to the events of the past.

This paper and the one that immediately followed it in the same issue (Bennett et al. 1977) are the reasons so many of you are here today. They set the stage for what came to be known as accelerator mass spectrometry (AMS), and over these past days of talks I have been quietly amused to note the ideas from those early times which are still reflected in today's research, as well as those many achievements which go far beyond my early dreams.

In this rambling talk, I will not even try to put the events of those early days into general historical perspective; if that is indeed of interest, it is a task best left to an objective historian. John asked me to describe how my work came about and so I'm only going to discuss those events and mention those people which led to the publication of our paper.

The only way I could think of to do that is to start at the beginning. Like that big bowl of spaghetti with only one noodle, it's all connected. Try to keep that in mind as I seemingly wander far off topic.

\section{THE BACKGROUND}

In 1972, I was granted a PhD in low-energy nuclear physics by McMaster University ("Mac") in Hamilton, Ontario. I was one of many graduate students who helped establish Mac's FN Tandem van de Graaff accelerator laboratory. Under Dennis Burke's supervision, my first task was to help assemble an Enge split-pole magnetic spectrograph for use in the nuclear reaction studies which formed the basis of my $\mathrm{PhD}$ research and that of many others. This large magnetic analyzer had a long focal plane on which photographic plates were used as detectors, and so experimental turnaround times were long, as the exposed plates had to be first developed and then tediously counted under a microscope. Suitable solid-state particle detectors were not then available to us.

There being no jobs available in the field when I graduated, I naively applied for an advertised position to construct a ${ }^{14} \mathrm{C}$ laboratory for a government institution in Vancouver, BC. I didn't get the job.

(C) 2010 by the Arizona Board of Regents on behalf of the University of Arizona

Proceedings of the 20th International Radiocarbon Conference, edited by A J T Jull

RADIOCARBON, Vol 52, Nr 2-3, 2010, p 219-227 
In 1973, I decided to try to combine physics with an old interest from undergraduate days, archaeology. I somehow convinced the only physicist in Canada with a similar interest, Dave Huntley at Simon Fraser University, to take me on as a post-doctoral fellow in the emerging field of archaeometry. In particular, the then-new research in thermoluminescence (TL) dating intrigued me, and I also got involved in using X-ray fluorescence analysis to identify obsidian artifacts. I have been at SFU ever since.

At the time, the center of the archaeometric world was at 6 Keble Road in Oxford. They were doing the defining work in TL dating, and so I arranged a 6-week visit in late 1974 to learn what I could. This visit was to be pivotal; I met the people there, made many good friends, and learned a lot about TL dating. (I also learned that much of the work had to be done in the dark, and I need light.) At about this time, the new SFU Archaeology Department began to contemplate hiring an archaeometrist who would establish a ${ }^{14} \mathrm{C}$ dating facility. With a young family, I needed a solid job, so I shifted research interests. An off-shoot consequence was that, while I moved out of luminescence dating, Dave Huntley became increasingly interested and went on to establish the basis for optical luminescence dating, the method so widely used today.

I started as Assistant Professor of Archaeology at SFU in the fall of 1975. My responsibilities were to teach archaeometry, design, build, and direct a ${ }^{14} \mathrm{C}$ lab, and to improve methods for ${ }^{14} \mathrm{C}$ dating. As I had been doing my homework, I started immediately to plan a small, traditional beta-counting facility. In the spring of 1976, using a contact I had made while in Oxford, I went off to spend the summer at Bob Otlet's ${ }^{14} \mathrm{C}$ lab in Harwell, England. There, both proportional and liquid scintillation counting (LSC) were in use, and I could get direct experience "on the line" processing routine ${ }^{14} \mathrm{C}$ samples. There were many operating ${ }^{14} \mathrm{C}$ labs in the British Isles at the time and I visited all of them, including Gordon Pearson's lab in war-torn Belfast. I learned a lot, and I especially learned that waiting for ${ }^{14} \mathrm{C}$ atoms to decay takes much patience and much sample material.

${ }^{14} \mathrm{C}$ measurement methodology figured in at least 2 critical discussions that summer. One was with Gordon Brown, a nuclear physicist at Bradford University and part of their archaeometry research group. The second was with Robert Hedges at Oxford. Robert was in the process of switching research interests, and planned to take sabbatical leave that fall at a lab in Berkeley, California. He thought it might be possible to use lasers to sufficiently enrich ${ }^{14} \mathrm{C}$ samples that the ${ }^{14} \mathrm{C}$ could be detected directly using mass spectrometry. As SFU is just a short flight north, I invited him to come to SFU sometime the following spring to give a seminar on his research.

On my return to SFU that fall, I began constructing a standard LSC lab, as I concluded this method would best suit our departmental circumstances. By that time, the critical role of stable isotope measures $\left(\delta^{13} \mathrm{C}\right.$ values) in ${ }^{14} \mathrm{C}$ dating was becoming ever more evident. The larger labs had expensive isotope ratio mass spectrometers, and I was concerned that we could not afford one at our small lab. It was at some time during that summer, fall, and early spring that I began to wonder if my old "friends" the tandem accelerator and the Enge spectrograph could be used as a special mass spectrometer with sufficient sensitivity to detect ${ }^{14} \mathrm{C}$ atoms at natural concentrations.

(An aside here: These ideas were interrupted by another, which failed gloriously shortly after conception. I can only now discuss it, as I am about to retire. The X-ray energies from mu-mesic carbon isotopes are sufficiently different that one could contemplate, in principle, doing a form of XRF to detect ${ }^{14} \mathrm{C}$. As SFU is one of the universities in TRIUMF (Tri-University Meson Factory), there was a supply of mesons at near hand. At what flux? I had no idea. What was the capture cross-section? I had no idea, nor did my friend Ralph Korteling, an SFU nuclear chemist who worked at TRIUMF. But Ralph knew someone who did know, and in one of those infamous calculations on a napkin, he 
determined that a single measurement would entail running the big cyclotron flat out for a year. At 30 million dollars per sample, that seemed impractical!).

In early 1977, I was actively considering going to McMaster, stuffing some Modern carbon into the ion source somehow, pointing the old Enge straight down the beam line and seeing what came out on the focal plane. Some old notes show that I phoned my friends at the Mac lab to discuss the possibility. The problem was detection, as photographic plates left much to be desired.

The 1977 Archaeometry Conference was held in Philadelphia March 16-19, and I have only 2 memories of it. One is of the fabulous dinner held in the Egyptian Room of the museum, surrounded by hieroglyphs, sarcophagi, and statuary. The second is of a quiet conversation with Gordon Brown, who took me aside to tell me that a colleague, Roy Middleton, had just shown that negative nitrogen atoms were too unstable to accelerate in a tandem. On the plane ride home, the tandem/Enge plan became truly pertinent. With its external negative ion source and the possibility of simultaneously accelerating more than one isotope, the tandem could be configured as a large isotope ratio mass spectrometer in which one could compare sample against standard in the usual carbon isotopic manner. If nitrogen couldn't get out of the negative source, a major obstacle was removed. What detector could I use?

Sometime in the first week of May, after lectures were over, exams marked and grades posted, I found in my mailbox a copy of Science with a fascinating article by a Richard Muller (who was he?) at Berkeley. I sat on the secretary's wastebasket and read it through 3 times before discomfort made me leave. Muller suggested that a cyclotron could be used to detect ${ }^{14} \mathrm{C}$ at natural concentrations. He had not yet succeeded with carbon, but it was excellent work. I immediately concluded that even if he could detect ${ }^{14} \mathrm{C}$, it would be very difficult to use a cyclotron for accurate concentration measurements. For many reasons, the tandem was a much better choice. (Later, when I came to know Rich, I phoned to say that his small cyclotron would never work but when it did, could I please be first in line for a set of blueprints.) What Muller's article did provide was the answer to my remaining problem, the detector. I had no idea how his “energy telescope” worked, so I asked Ralph Korteling. Ralph explained the physics, and it became clear that not only was this the detector for the job, but that the Enge spectrograph was probably no longer needed. Now it was time to get an experiment underway; where could one get one of these things, and how much did they cost? (I was too new in the business to have any research funds.) In one of those moments that stick in memory, Ralph grinned, reached into his desk drawer and held up an object, saying "I think this one would do the job very well." Shortly after, he agreed to take on the critical particle identification portion of an experiment at the McMaster tandem.

\section{THE EXPERIMENT}

I recently found notes dated 10 May 1977 that give our detailed experiment plans and so they must have been made within days. As I recall, my first request for beam time on the Mac tandem was turned down. To this day, I don't know whether that was due to pressure on the machine or whether my old friends thought I had simply gone crazy. At the next beam request time, I put on all the pressure I could. Perhaps by this time people had either grown curious, or no one else wanted the machine anyway. In any case, we were given the accelerator for 3 or 4 days starting Wednesday morning, June 1st.

I made charcoal from some wood of Modern concentration and arrived on the preceding Friday to work out the problem of getting it into the Cs-sputter source. Peng, the ion-source technician, came up with a solution. Ralph arrived Monday night, and we spent the following day getting ready. By 
this time, there was lots of interest in the lab, and a grad student, Bill Stott, offered to help Ralph set up his detectors and electronics, because "what we were planning to do sounded really interesting."

I set about getting the tandem going. It was in poor shape and had been sparking a lot in previous days. We had planned to run at $8 \mathrm{MV}$ on the terminal, but it would only hold $7 \mathrm{MV}$, and so came about a standard that we were to use for many years. Soon, my old friends Dennis Burke, Jim Waddington, and John McKay were helping out with the machine. These Mac people stuck with us night and day until the end. Without them, we likely wouldn't have succeeded.

It was obvious from the outset that there were going to be problems stabilizing the tandem, as it would not be possible to use a stable beam for energy control while we tried to find the rare ${ }^{14} \mathrm{C}$ ions. Further, Ralph's expensive detector would be ruined by chance exposure to even a small beam of ions.

Figure 1 has a crude schematic of the setup we used. The detectors were placed in a simple scattering chamber on the "zero-degree" beam-line from the analyzing magnet. This chamber allowed us to place a thin gold foil at the target position and to rotate a Faraday cup, a cheap solid state detector, and the expensive telescope about an axis centered on the foil. That way, we could tune the ${ }^{12} \mathrm{C}$ beam through the entire machine into the Faraday cup and then change all relevant optical controls to those calculated for ${ }^{13} \mathrm{C}$. That these changes were correct could then be tested by measuring the ${ }^{13} \mathrm{C}$ current, providing assurance that we could then make the appropriate changes for the ${ }^{14} \mathrm{C}$ ions. While stabilizing the tandem voltage was possible using slit-control for the 2 stable isotope beams, for the ${ }^{14} \mathrm{C}$ ions we had to use GVM control, which was not very reliable on the poorly functioning machine. To prevent chance exposure of the sensitive telescope to a large beam, this controller was also used to trigger a device used in other experiments for beam pulsing, such that when the terminal voltage drifted, any beam was deflected away. (I can't remember where in the beam-line this deflector was positioned; I have drawn it at the high-energy end in the illustration.)

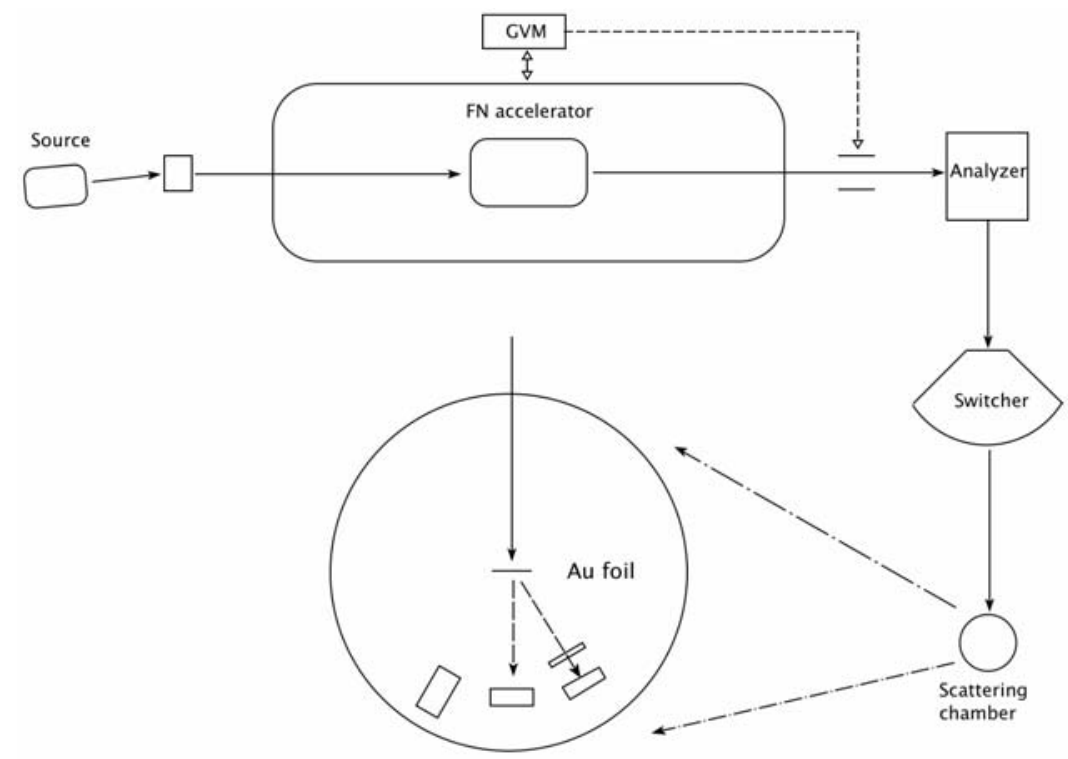

Figure 1 A basic schematic diagram of the equipment configuration for the SFU experiment at McMaster. 
Since we had no idea what strange ions would be coming down the pipe in the ${ }^{14} \mathrm{C}$ slot, we would limit intensity by using Rutherford scattering from the gold foil, gradually moving the cheap detector toward zero angle, giving us a first view of the intensities and energies of any particles. If these could be reduced to workable numbers, we could insert the telescope and then remove the gold foil.

While that sounds easy, it entailed hours of tuning and retuning and then doing it again, only to find particle intensities that overwhelmed the detectors. At one point (very late at night, I think), we were about to give up, when the proverbial lightbulb in my head flashed, and I narrowed the horizontal high-energy object slits to restrict the off-axis beams getting through the inflection magnet. (While this seems obvious today, it wasn't then.) Shortly after, we could put the telescope at zero degrees with no gold foil, and Ralph said, pointing to a little peak on the PDP-9 computer 1-dimensional display "there it is, that can't be anything else." A few weeks ago, in a mouse-eaten cardboard box containing old files to be thrown out, I found a strip-chart output ( $\Delta \mathrm{E}$ vs channel number) with a number of peaks identified in my handwriting. It is not dated, but given the notations, I believe it to be the plot from that first detection. A photo is given in Figure 2. While I remember the "eureka" moment, I did not record it in my log book, as it seems we were already putting together a long run to collect a good spectrum for later computer analysis at SFU. For those interested in such things, I can only narrow the time of first detection to sometime in the period June 1-2.

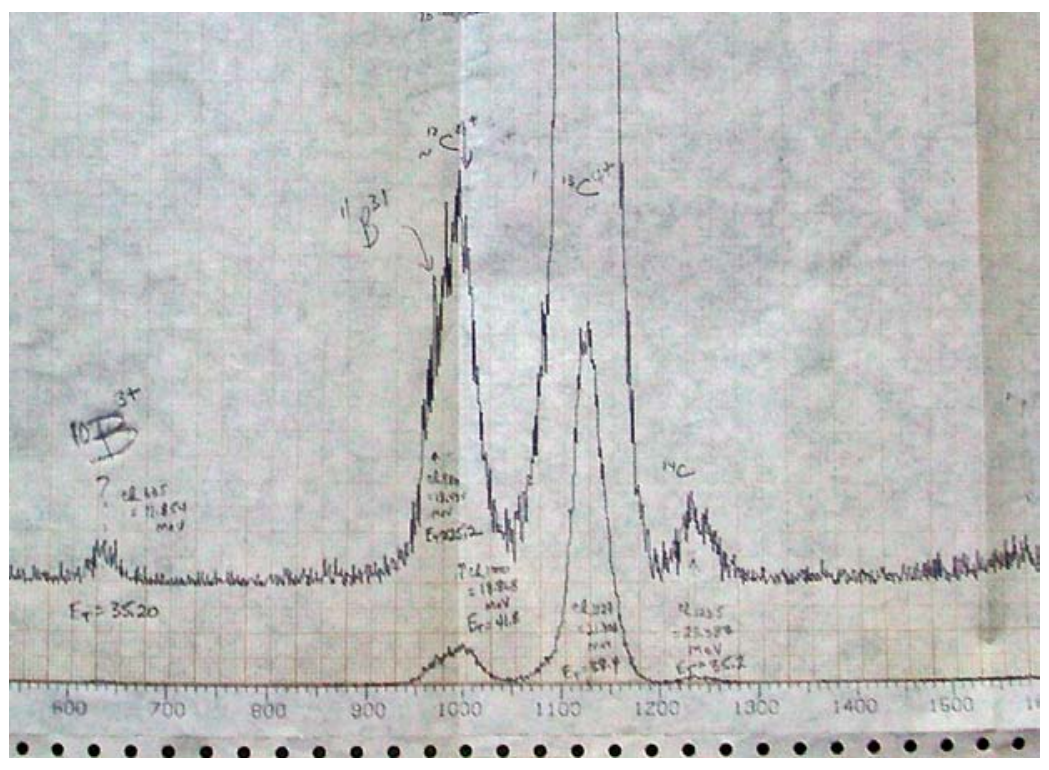

Figure 2 The relevant portion of the primitive strip-chart output of our first detection of ${ }^{14} \mathrm{C}$

The run that followed was long and marked only by an hour-long search to find the button to reset the radiation protection monitor that had tripped, inserting the low-energy cup and thus shutting down the experiment.

We left for home that weekend with a large magnetic tape of detected events that would have to be processed by the big computer at SFU before we could really see what we had measured. Until that was done, the only thing we had to show was the little peak on the strip chart.

When I came into the office at SFU early the next week, there were 3 new problems to be faced. First, Robert Hedges was coming the following day to give the talk on his research as we had 
arranged the previous year! When he arrived, I could not bring myself to tell him that we had detected ${ }^{14} \mathrm{C}$ at natural concentrations; that seemed far too impolite in the circumstance. He was staying with a friend who did tell him, and he came into the lab the following day anxious to hear about it and to see our evidence. All I could then show him was the little peak on the plot, of which he was very politely very skeptical.

Our second problem later helped change his mind. After he left, I received a phone call from my McMaster friends to inform me that a New York newspaper article described the breakthrough work of another group that had used the tandem at Rochester University to detect ${ }^{14} \mathrm{C}$ at natural concentrations. What should we do? Issue a press release as well? Or? Ralph and I decided to proceed in the time-honored manner; we would submit a paper to our scientific peers before making any public statements, and then let things work out as they would. In any case, it was both amusing and gratifying that 2 groups independently would make these discoveries within days: Taken together with Rich's previous attempt, there now remained no doubt that a viable new method for ${ }^{14} \mathrm{C}$ dating was in the offing.

Soon after, Roger Toren at SFU had converted the raw data on our tape into a 2D plot (as published in the paper and reproduced in Figure 3), which I came to call the topographical map of never-ever land, as the sensitivity to rare events was incredible. The written paper was soon completed and we submitted it to Science. Shortly after, I received a note from the Rochester group with a dated copy of a manuscript they had also submitted to Science. I replied with a copy of our own, which had been submitted 2 days before theirs. As it turned out, ours arrived at Science a day earlier, and so the 2 were published back-to-back, ours first. While this was to cause much angst, I still believe it was a wonderful example of science at work. In the space of a few weeks, a new field of research came about. Long before these 2 articles were in print, many laboratories around the world were in hot pursuit. Certainly, Robert soon returned to Oxford to plan what would become the Oxford Radiocarbon Accelerator Unit. He later wrote that on the day he left Berkeley, he achieved 100 -fold ${ }^{14} \mathrm{C}$ enrichment, but that it no longer seemed important.

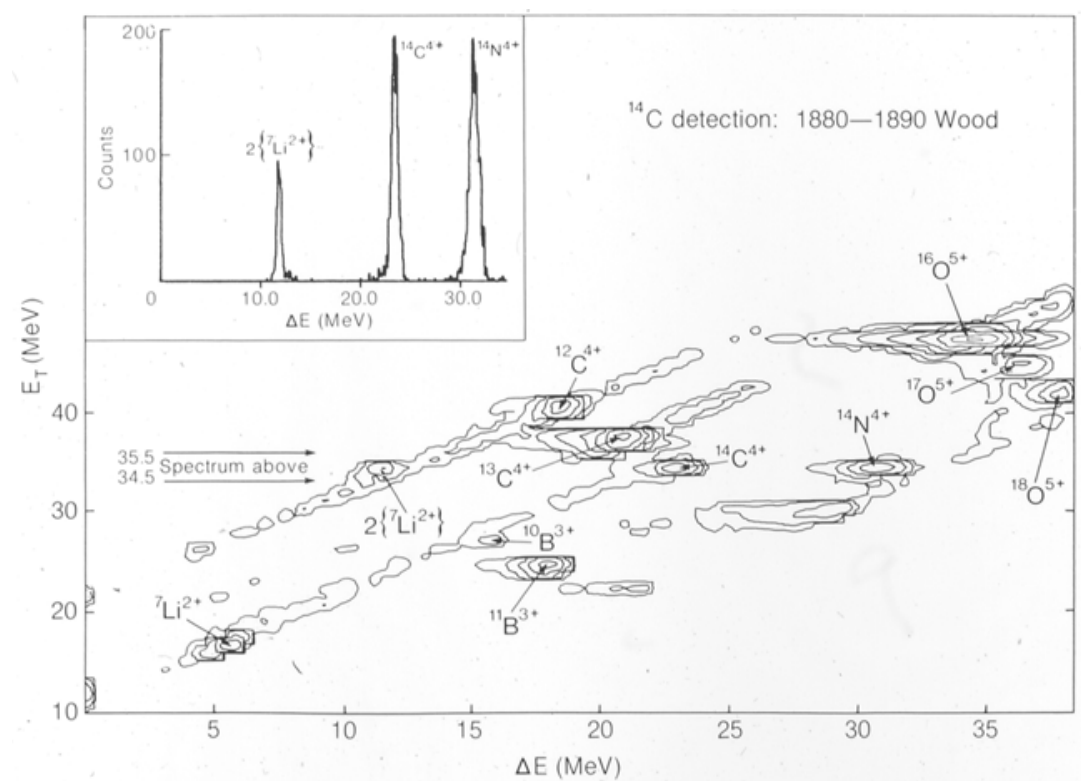

Figure 3 The 2-D plot as published in Science 
My third problem was local. The LSC laboratory I had constructed for the Archaeology Department was then starting to produce first results, and in effect, I had just rendered it obsolete. Moreover, I had used some of my lab development funds to pay for the trip to Mac to do so. The department chairman was displeased, and I received a very stiff note of reprimand.

And that is my story of a good experiment.

\section{EPILOGUE}

From those few days emerged a small AMS research team, the RIDDL group, which had headquarters at Simon Fraser but worked at McMaster. In the beginning, Ralph Korteling and I tried hard to conduct further research at Mac, but that was very difficult not only because of the distance, but as we were unable to obtain Canadian funding support. Later, support from America enabled us to hire John Southon, and subsequent Canadian funding the following year provided the means to hire John $\mathrm{S}$ Vogel. Soon after, Tom Brown joined the group, first as graduate student and then as research associate. Despite our small size, I think we did some useful work at RIDDL before circumstance caused its closure. We made an attempt to establish a joint AMS lab in Vancouver (together with Minze Stuiver, who would supply an old FN tandem from the University of Washington), but it was not funded. Southon, Vogel, the FN, and later Brown then went south to join the emerging AMS group at the Lawrence Livermore Laboratory in California. Under the very energetic direction of Jay Davis, this group established the LLNL CAMS facility as an institution noted for its front-line AMS research. Vogel has since retired, after a vigorous career establishing AMS as a tool in bioscience, but Southon and Brown are still very active in the field and are here in the audience today.

While preparing this presentation, I found in my files some old, faded RIDDL photos that may be of interest in a historical sense, as the consequences are very much in evidence at this conference. I reproduce them in Figures $4-8$ below.

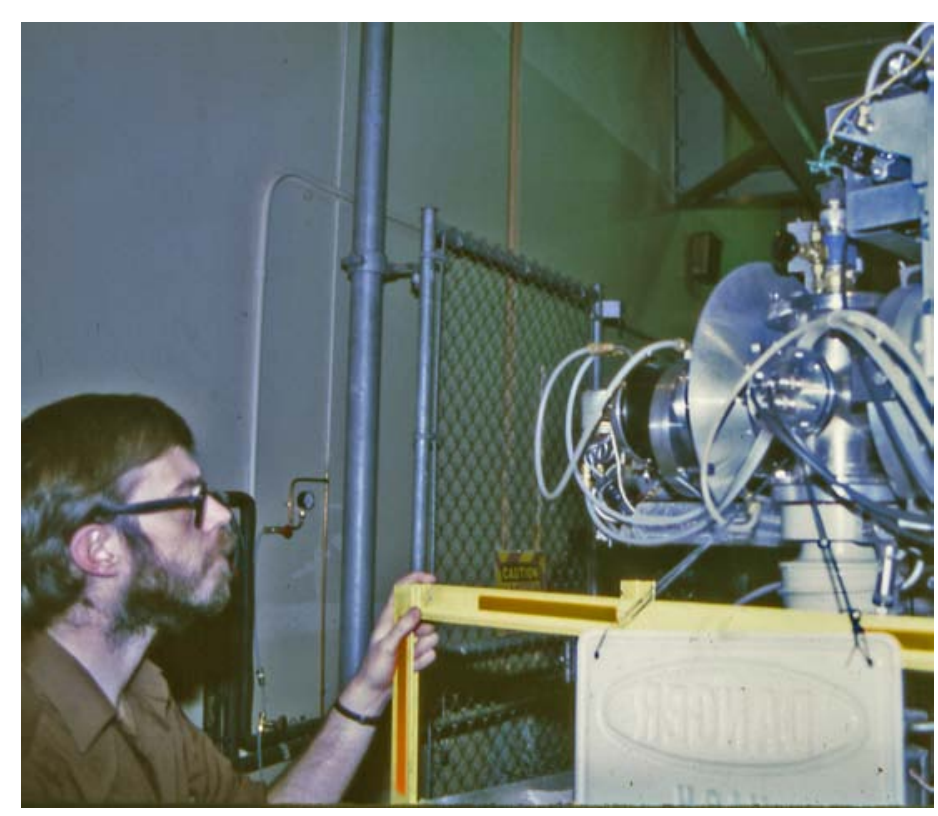

Figure 4 A much younger John Southon and his home-built ion source, the first of many. 


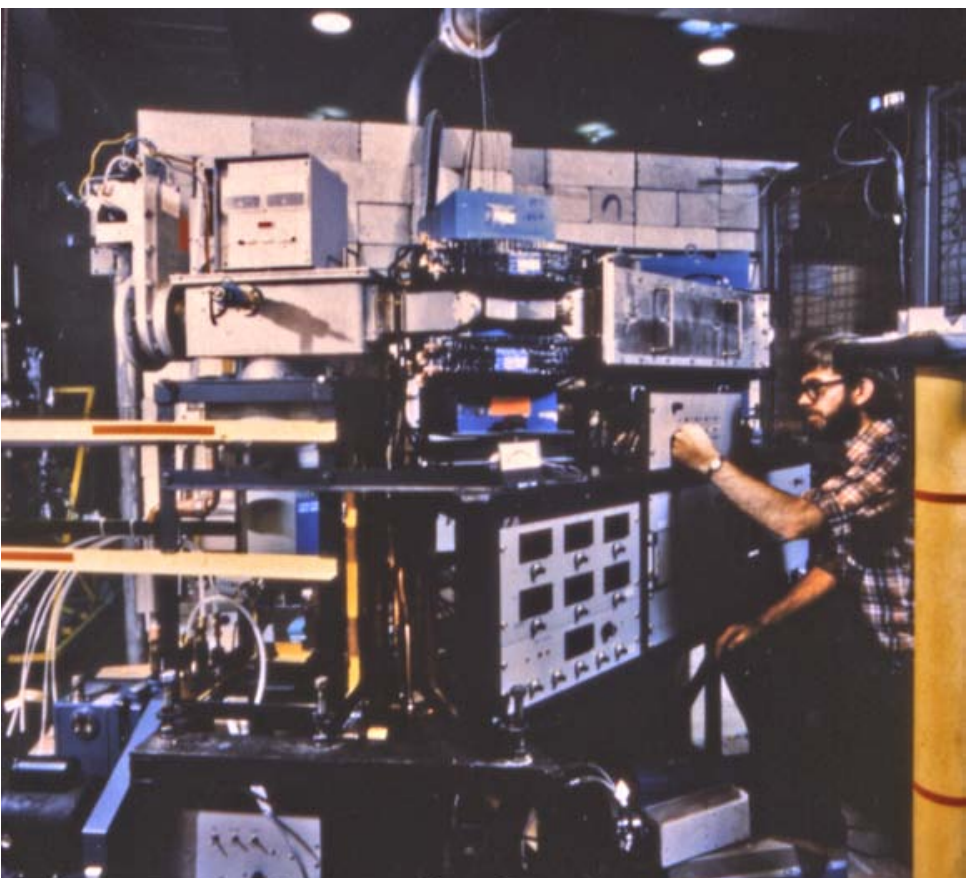

Figure 5 John Southon and the first ever simultaneous injector. (A much more modern commercial variant of the concept was advertised at this conference.)

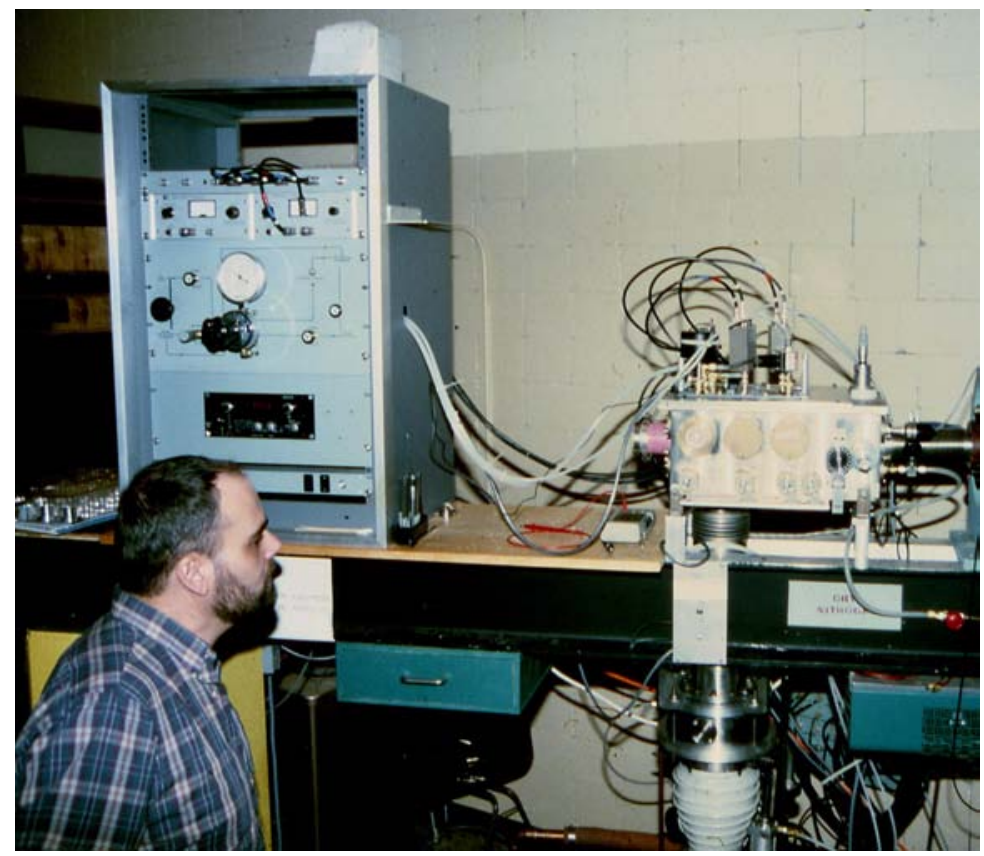

Figure 6 Young John S Vogel (now retired) who went on to develop AMS for use in biochemistry. 


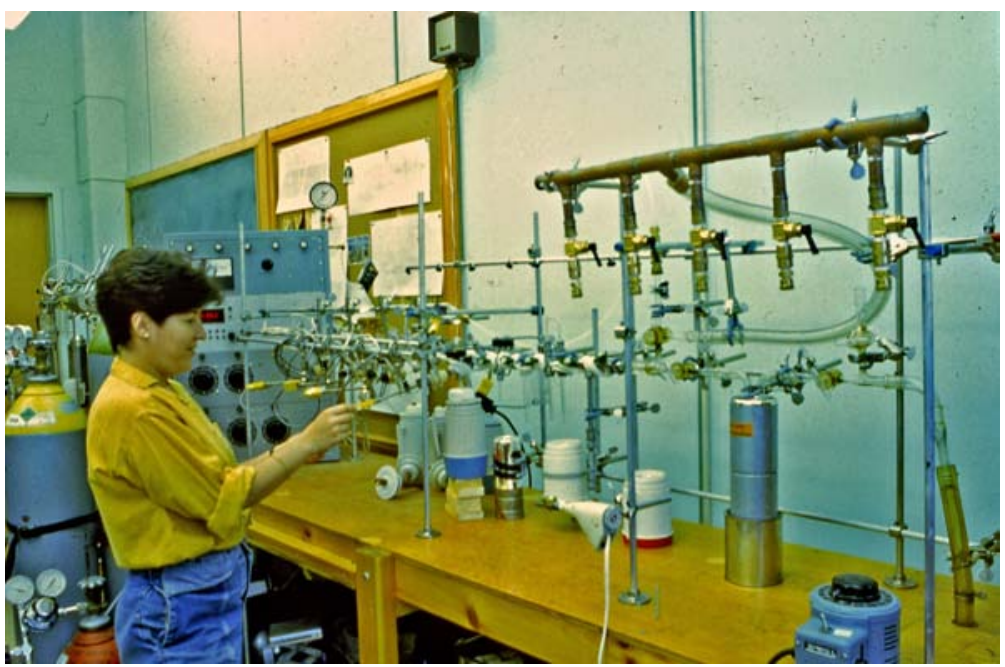

Figure 7 Graduate student H Roman operating John Vogel's “graphitizer” for preparing carbon samples, the progenitor of most (all?) of its kind.

\section{A photo of a young, long-haired Tom Brown working on his ultra-filtration bone preparation method while flooding the SFU lab is unfortunately not available.}

Figure 8 Using ultrafiltration for bone preparation was a Tom Brown invention in the mid1980s. It was much discussed at this conference, but to my dismay, I have no photo of Tom doing the work, so I had to make do with the words above.

\section{POST-SCRIPTUM}

I wish to end this written version of my talk with some simple statements:

My heartfelt thanks to Ralph, John, John, and Tom for the interesting times we have had together, both those which were exhilarating and those which weren't. It is an honor to still count you all as personal friends some 3 decades later.

McMaster, thanks for being so hospitable in hosting an SFU group for so many years at the "Low Altitude SFU Eastern Campus" in your Nuclear Science Building. That was most generous, but then, in all of this, it was good science which remained most important.

\section{REFERENCES}

Bennett CL, Beukens RP, Clover MR, Gove HE, Liebert RB, Litherland AE, Purser KH, Sondheim WE. 1977. Radiocarbon dating using electrostatic accelerators: negative ions provide the key. Science 198(4316): 508-10.

Nelson DE, Korteling RG, Stott WR. 1977. Carbon-14: direct detection at natural concentrations. Science 198(4316):507-8. 